\title{
Mesleki Gürültüye Bağlı İşitme Kaybının Medikolegal Değerlendirilmesi
}

\author{
Medicolegal Assessment of Occupational Noise Induced Hearing Loss
}

\author{
Sadık TOPRAK (iD) , Zarif Asucan ŞENBAŞ (iD , Abdullah Coşkun YORULMAZ
}

\section{ÖZET}

Gürültünün, özellikle de işyerinde maruz kalınan gürültünün en önemli olumsuz sonucu, mesleki gürültüye bağlı işitme kayıplarıdır (GBIK). İş yerinde gürültü seviyesi ve gürültüden korunma ile ilgili yasal düzenlemelerle belirlenmiş standartlar bulunmasına rağmen mesleki yüksek seviyelerde gürültüye maruz kalma oranı halen yüksektir. Mesleki gürültüye maruz kalmanın yüksek prevalansına rağmen, tespit edilen vaka sayısının bu kadar düşük olmasının en önemli nedeni, medikolegal değerlendirmede yapılan eksiklikler olarak karşımıza çıkmaktadır. Mesleki GBíK'nin medikolegal açıdan değerlendirilmesinde dünyada çeșitli çalıșmalarla tanı kriterleri belirlenmeye çalıșılmıștır. Bu derlemede amacımız, bu çeșitli değerlendirme kriterleri ile Türkiye'de mevcut yasal durumun derlenerek GBİK olgularında medikolegal değerlendirme yapılabilmesine yönelik bir algoritma önerisinin ortaya konmasıdır.

Anahtar Kelimeler: Adli Tıp, Meslek Hastalıkları, Mesleki Gürültü Maruziyeti, Ton Odyometri, Presbiakuzi, Mesleki İșitme Kaybı

\section{ABSTRACT}

The most important negative consequence of noise, especially workplace related noise, is occupational noise induced hearing loss (NIHL). Although there are standards set by legal regulations on noise level and noise protection in the workplace, high levels of occupational noise exposure prevalence is still high. Despite the high prevalence of exposure to occupational noise, the most important reason for the low number of cases detected is the deficiencies in the medicolegal evaluation. Diagnosis criteria have been tried to be determined for the medicolegal evaluation of occupational NIHL by various studies in the world. In this review, our aim is to propose an algorithm with medicolegal aspects, while compiling those variety of criteria and the existing legal situation in Turkey.

Keywords: Forensic Medicine, Occupational Diseases, Occupational Noise Exposure, Pure Tone Audiometry, Presbyacusis, Occupational Hearing Loss

Sadık TOPRAK I sadik_toprak@yahoo.com

İstanbul Üniversitesi, İstanbul Tıp Fakültesi, İstanbul Türkiye

Istanbul University, Istanbul Faculty of Medicine, Istanbul, Turkey

Zarif Asucan ŞENBAŞ (Sorumlu Yazar/Corresponding Author) I asucansenbas@gmail.com

İstanbul Üniversitesi, İstanbul Tıp Fakültesi, İstanbul Türkiye

Istanbul University, Istanbul Faculty of Medicine, Istanbul, Turkey

Abdullah Coşkun YORULMAZ | cyorulmaz@ku.edu.tr

Koç Üniversitesi, Tıp Fakültesi, İstanbul, Türkiye

Koc University, Faculty of Medicine, Istanbul, Turkey 


\section{GİRIŞ}

Gürültü, genel anlamda işitilmesi istenmeyen, rahatsız olunan sesler için kullanılan bir terimdir. Hem günlük hayatta, hem de mesleki olarak yaygın şekilde karşılaşılmasının yanında, sağlıkta işitsel veya işitsel olmayan olumsuz etkilere neden olur. Yapılan çalışmalar gürültüye maruz kalmanın sıkıntı veren bir durum olduğunu, uyku düzenini bozarak gündüz uykusuna neden olduğunu, personel performansını etkilediğini, hipertansiyon ile kardiyovasküler hastalık oluşumunu artırdığını ve okullarda bilişsel performansı bozduğunu göstermiştir [1]. Gürültünün, özellikle de işyerinde maruz kalınan gürültünün en önemli olumsuz sonucu, gürültüye bağlı mesleki işitme kayıplarıdır. Dünyada erişkin başlangıçlı işitme kayıplarının \%16’sını gürültüye bağlı mesleki işitme kayıpları oluşturmaktadır [2]. Amerika Birleşik Devletleri'nde 22.4 milyon çalışan iş yerinde potansiyel olarak tehlikeli seviyede gürültüye maruz kalmaktadır [3]. Yine Amerika Birleşik Devletleri'nde gürültüye maruz kalan 1 milyon çalışan arasında yapılan bir çalış- mada işitme kaybı açısından en yüksek riskli iş alanları madencilik, ahşap ürün imalatı, inşaat ve emlakçılık olarak bulunmuştur [4]. Türkiye'de iş kollarını gürültü riski açısından geniş bir şekilde araştıran bir çalışma bulunmamakla birlikte, çeşitli iş kolları için yapılmış araştırmalar mevcuttur. Örneğin döküm iş kolundaki iş yerleri arasında yapılan bir çalışmada; işyerlerinin \%62'sinde 85 desibelden yüksek seviyede gürültü, çalışanların \%23'ünde gürültüye bağlı işitme kaybı (GBİK) saptanmıştır [5].

İş yerinde gürültü seviyesi ve gürültüden korunma ile ilgili yasal düzenlemelerle belirlenmiş standartlar bulunmasına rağmen mesleki yüksek seviyelerde gürültü maruziyeti prevalansı halen yüksektir [6]. Bu yüksekliğe karşın, Grafik 1 'de görüleceği üzere meslek hastalığı tanısı alanların içinde gürültüye bağlı işitme kaybı tanısı (H83.3-İç kulakta gürültünün etkileri) alan kişi sayısı son derece düşüktür [7].

Mesleki GBİK’nin yüksek prevalansına rağmen, tespit edilen vaka sayısının bu kadar düşük olmasının en önemli nedeni, medikolegal değerlendirmede yapılan eksiklikler

Grafik 1: 2013-2018 yılları Arasında Sosyal Güvenlik Kurumu 5510 Sayılı Kanunun 4-1/a Maddesine Göre Meslek Hastalığı Tanısı Alanların İçinde Gürültüye Bağlı İşitme Kaybı Tanısı (H83.3-İç Kulakta Gürültünün Etkileri) Alan Kişi Sayıları

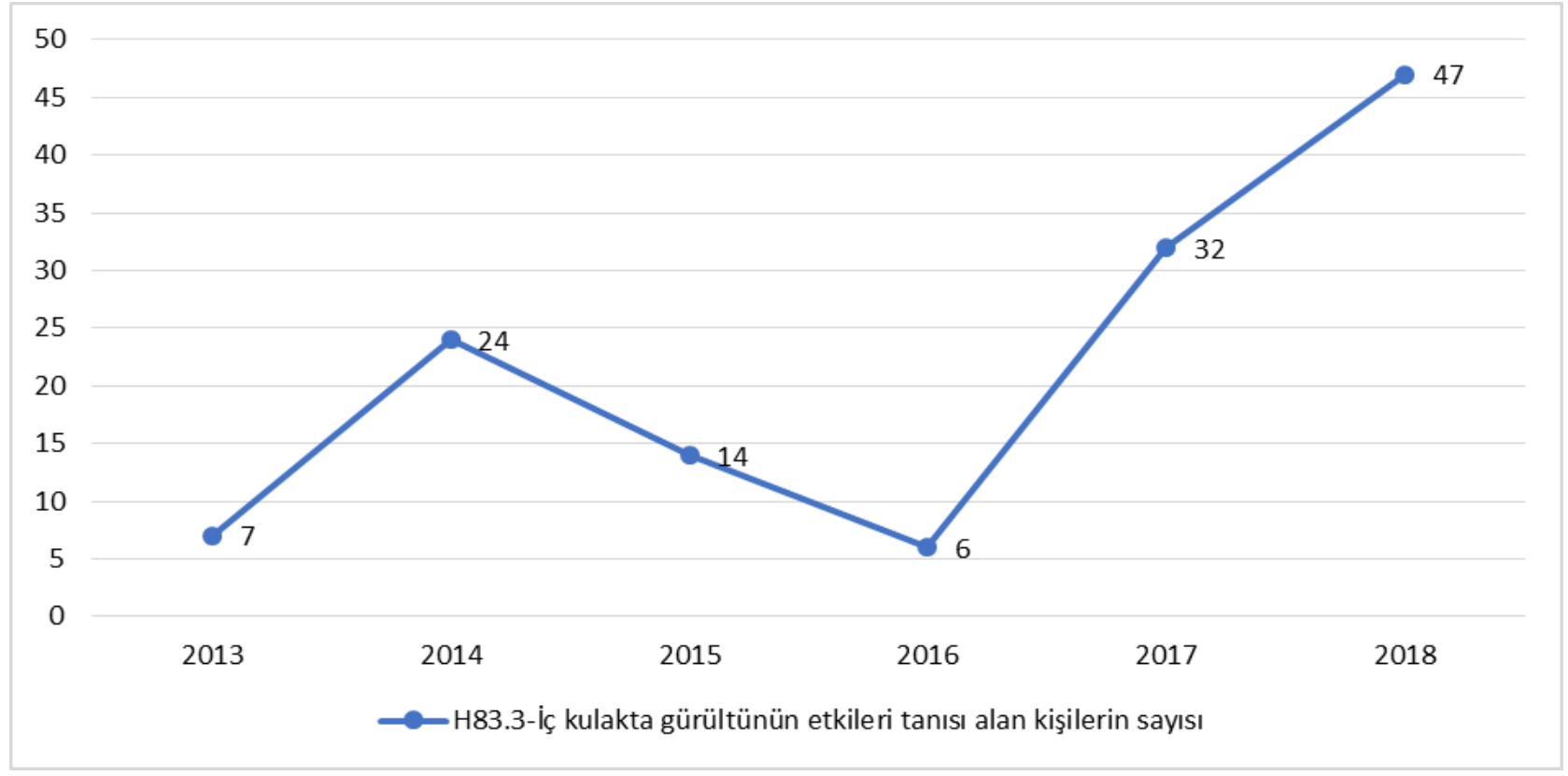


olarak karşımıza çıkmaktadır. Bu derlemede amacımız, GBİK'ye medikolegal yaklaşım yönteminin ortaya konmasidır.

\section{GÜRÜLTÜNÜN İSi̇TME ÜZERİNDEKI ETKİLERI}

İşitme sırasında iç kulaktaki Korti organında bulunan silyalı hücreler reseptör görevi görerek sesten meydana gelen mekanik enerjiyi beyne iletilmek üzere sinirsel ileti haline getirirler. Gürültü maruziyeti ile silyalı hücrelerde glikojen depoları azalmakta, serbest oksijen radikallerinin oluşumu hızlanmaktadır. Geçici eşik değişikliğinde; gürültü maruziyetine bağlı silyalı hücrelerde meydana gelen bu değişiklikler, işitme hassasiyetinde azalmaya neden olmaktadır. Geçici eşik değişikliği genellikle 16-48 saat arasında sürmekte ve sonrasında işitme kaybı düzelmektedir [8]. Gürültü şiddeti ve süresi daha yüksek ise silyalı hücrelerin apoptozisi, koklear sinir dejenerasyonu, Korti organı hasarı (endolenf ve perilenfin birbirine karışması, Korti organının baziller membrandan ayrışması, hücreler arası bağlantılarda bozulma) gibi mekanizmalarla geri dönüşümsüz hasar meydana gelmekte, bu da kalıcı eşik değişikliğine neden olmaktadır. Serbest oksijen radikallerinin artması, glutamat nörotransmitterinin yarattığı eksitotoksisite ve silyalı hücrelerde serbest kalsiyum miktarının artması, apoptotik ve nekrotik silyalı hücre ölüm yollarını tetikleyebilecek metabolik yollar olarak karşımıza çıkmaktadır [9]. Baş bölgesi ve kulağın kısa süreli, çok şiddetli bir gürültüye maruziyeti sonrası akustik travma meydana gelebilmektedir. Akustik travmada kulak zarında, orta kulak kemikçiklerinde veya koklear sinirde hasarın da eşlik ettiği işitme kaybı gelişmektedir [10]. Ateşli silahlar, havai fişek gösterileri ve müzikli eğlence yerleri bu şekilde bir gürültünün kaynağı olabilir. Akustik travmada işitme kaybı gürültü maruziyetinin hemen sonrasında başlamakta, genellikle kulak çınlaması şikayeti eşlik etmektedir.
Görüldüğü üzere gürültünün işitme duyusuna etkisi geçici eşik değişikliği, kalıcı eşik değişikliği ve akustik travma olmak üzere üç şekilde karşımıza çıkabilmektedir. Gürültüye bağlı işitme kaybı ise zarar verici düzeyde gürültüye maruz kalınması sonucu gelişen sensörinöral tipte bir işitme kaybıdır. Her ne kadar geri dönüşümsüz bir hasar olsa da tamamen önlenebilir bir durumdur ve gürültü maruziyetinin sonlanması ile ilerlemesi durmaktadır. Aynı şiddette gürültüye maruz kalmaya devam edenlerde ise yaşla birlikte işitme kaybının ilerleme hızı azalmaktadır.

\section{MESLEKİ GBİK TANISININ MEDİKOLEGAL AÇIDAN KONULMASI}

GBİK tanısı maruz kalınan gürültünün tipi ve şiddetinin sorgulanması, başvuranın tıbbi anamnezi, muayene ve işitme fonksiyonunun değerlendirilmesi sonrasında konulabilir [11]. Mesleki GBİK’nin medikolegal açıdan değerlendirilmesinde dünyada çeşitli çalışmalarla tanı kriterleri belirlenmeye çalı̧ılmıştır.

Coles ve ark. (İngiltere) tanı için mutlaka gerekli olan üç kriteri yüksek frekanslarda görülen işitme kaybı (3, 4, veya $6 \mathrm{kHz}$ 'deki işitme kaybının 1 veya $2 \mathrm{kHz}$ 'dekinden en az $10 \mathrm{~dB}$ daha fazla olması), zarar verme olasıl lğı muhtemel şiddette gürültü maruziyeti (günde en az 8 saat süreyle 85 dB'den yüksek şiddette) ve odyometride yüksek frekanslarda $(3-6 \mathrm{kHz})$ görülen çentik veya tümsek (çentik yaşa bağlı işitme kaybının etkisiyle düzleşerek tümsek halini alabilir) olarak tanımlamıştır. Bu kriterlerin yanında tamamlayıcı faktörler olarak klinik tablo ile yaş ve gürültü maruziyetinin tanı ile uyumlu olması, diğer tanıların dışlanması ve bu tanı kriterlerini karşılamayan komplike vakaların (asimetrik işitme kaybı, başka hastalıklar zemininde gelişen GBİK vb.) değerlendirilme şekli belirtilmiştir [12]. Coles ve ark. önerdiği yönteme ek olarak Das ve ark (İngiltere) "Brewster Kuralı" olarak isimlendirdikleri yöntemle odyo- 
metri ile ölçülebilen ağırlık çizgisi (severity line) kavramını eklemiş, bu şekilde daha basit ve kesin olarak GBİK'yi tarayabildiklerini öne sürmüştür [13].

John ve ark. çalışmasında, Amerika Birleşik Devletleri'nde GBİK ölçümünün eyaletten eyalete farklılık gösterebildiğini, kullanılan matematiksel formüllerin odyometriye dayalı olduğunu ancak bu formüllerin büyük kısmının ampirik verilerle desteklenmediğini belirtmiştir [14].

\section{TÜRKIIYE'DE YASAL DURUM}

Ülkemizde Mesleki GBİK ile ilgili yasal düzenlemeler aşağıda sunulmuştur.

\section{A. Çalışanların Gürültü ile İlgili Risklerden Korunma-} larına Dair Yönetmelik (28.07.2013)

Bu yönetmelikte, günlük 8 saatlik bir iş günü için zaman ağırlıklı ortalaması (A tipi) en düşük maruziyet eylem değeri $80 \mathrm{~dB}$, en yüksek maruziyet eylem değeri ise $85 \mathrm{~dB}$ olarak belirlenmiştir. En yüksek ses basıncı (Ptepe) değeri ise en düşük $112 \mathrm{~Pa}$ ve en yüksek $140 \mathrm{~Pa}$ olarak belirlenmiştir. Buna karşılık maruziyet sınır değerlerinin $87 \mathrm{~dB}$ veya $($ Ptepe $)=200 \mathrm{~Pa}$ olduğu belirtilmiştir.

“Maruziyet Sınır Değerleri” uygulanırken, çalışanların maruziyetinin tespitinde, çalışanın kullandığı kişisel kulak koruyucu donanımların koruyucu etkisi de dikkate alınacağ1 vurgulanırken, "Maruziyet Eylem Değerleri”nde kulak koruyucularının etkisi dikkate alınmayacağı belirtilmiştir [15].

\section{B. 6331 sayılı İş Sağlığı Ve Güvenliği Kanunu} (20.06.2012)

Kanununun 4'üncü ve 10 'uncu maddelerinde işverenin iş sağlığı ve güvenliği yönünden risk değerlendirmesi yapmak veya yaptırmakla, mesleki risklerin önlenmesine yönelik tedbirleri almakla ve bu tedbirlere uyulup uyulmadığını denetlemekle yükümlü olduğu belirtilmektedir. Aynı kanu- nun 5 'inci ve 11 'inci maddelerine uygun olarak hangi önlemlerin alınması gerektiği belirlenmelidir. İş kazaları ve meslek hastalıkların bildirimi ile çalışanların sağlık muayenelerinin sıklığı ise 14 ve 15 'inci maddeler ile düzenlenmektedir [16].

C. Çalışanların Gürültü İle İlgili Risklerden Korunmalarına İlişkin Uygulama Rehberi (Ankara, 2018)

$\mathrm{Bu}$ rehberde, en düşük maruziyet eylem değeri $[80 \mathrm{~dB}$ (A)] aşıldığı zaman, önleyici odyometrik testler yapılmasıyla, gürültü nedeniyle işitme kaybının erken tanısının mümkün olabileceği vurgulanmıştır. Ayrıca ototoksik etkili kimyasallar, çözücüler ve tıbbi ilaçların listesi verilmiştir [17].

D. Meslek Hastalıkları ve İş ile İlgili Hastalıklar Tanı Rehberi (Türkiye'de İşyerlerinde İş Sağlığı ve Güvenliği Koşullarının İyileştirilmesi Projesi - TR0702.2001/001)

$\mathrm{Bu}$ rehberde, tek tanı aracinın saf ton odyometrisi olduğu belirtilmiştir. Gürültüye bağlı olan işitme kaybının genellikle $4000 \mathrm{~Hz}(4 \mathrm{kHz})$ civarında, bazen $6000 \mathrm{~Hz}$ de "V" veya "U" şeklinde bir çentiğe neden olduğu, çentiğin zamanla derinleşip genişlediği, genellikle $8000 \mathrm{~Hz}$ de düzeldiği kaydedilmiştir [18].

Tablo 1: Meslek Hastalıkları ve İş ile İlgili Hastalıklar Tanı Rehberi'ne göre GBİK Semptom ve Bulguları

Daima nörosensorial tiptedir.

Daima bilateraldir.

Yüksek frekanslardaki kayıp nadiren 75 dB'i, düşük frekanslardaki kayıp nadiren 40 dB'i geçer.

Gürültü maruziyeti sonlandıktan sonra ilerlemez.

Zaman geçtikçe işitme kayıp hızı azalır.

Kayıp, 3000-6000 Hz frekanslarda, 500-2000 Hz frekanslarda görülenden daha büyüktür. En çok $4000 \mathrm{~Hz}$ 'dedir. İlerlemiş hastalıkta bile $4000 \mathrm{~Hz}$ çentiği genellikle korunur.

Sabit gürültü düzeyine maruziyetlerde 3000,4000 ve 6000 Hz'lerdeki kayıp, maksimum seviyesine genellikle 10-15 yılda erişir.

Sinirlilik, yorgunluk gibi bulgular eşlik edebilir. 
E. 30.03.2013 tarihli ve 28603 sayılı Resmi Gazete'de yayımlanan Özürlülük Ölçütü, Sınıflandırma ve Özürlülere Verilecek Sağlık Kurulu Raporları Hakkında Yönetmelik

Söz konusu yönetmelikte, işitme testlerinin nasıl yapılacağı ve özür oranlarının nasıl hesaplanacağı ayrıntıları ile açıklanmıştır [19].
F. 20.02.2019 tarih ve 30692 sayılı Resmi Gazete'de yayımlanan Erişkinler İçin Engellilik Değerlendirmesi

\section{Hakkında Yönetmelik}

$\mathrm{Bu}$ yönetmelikte de engellilik değerlendirmesinde işitme testlerinin nasıl yapılacağı ve özür oranlarının nasıl hesaplanacağı ayrıntıları ile açıklanmıştır. 30.03.2013 tarihli ve 28603 sayılı Resmi Gazete’de yayımlanan Özürlülük Ölçütü, Sınıflandırma ve Özürlülere Verilecek Sağlık Kuru-

Tablo 2: Mesleki Gürültüye Bağlı İşitme Kaybının Medikolegal Açıdan Değerlendirilmesi

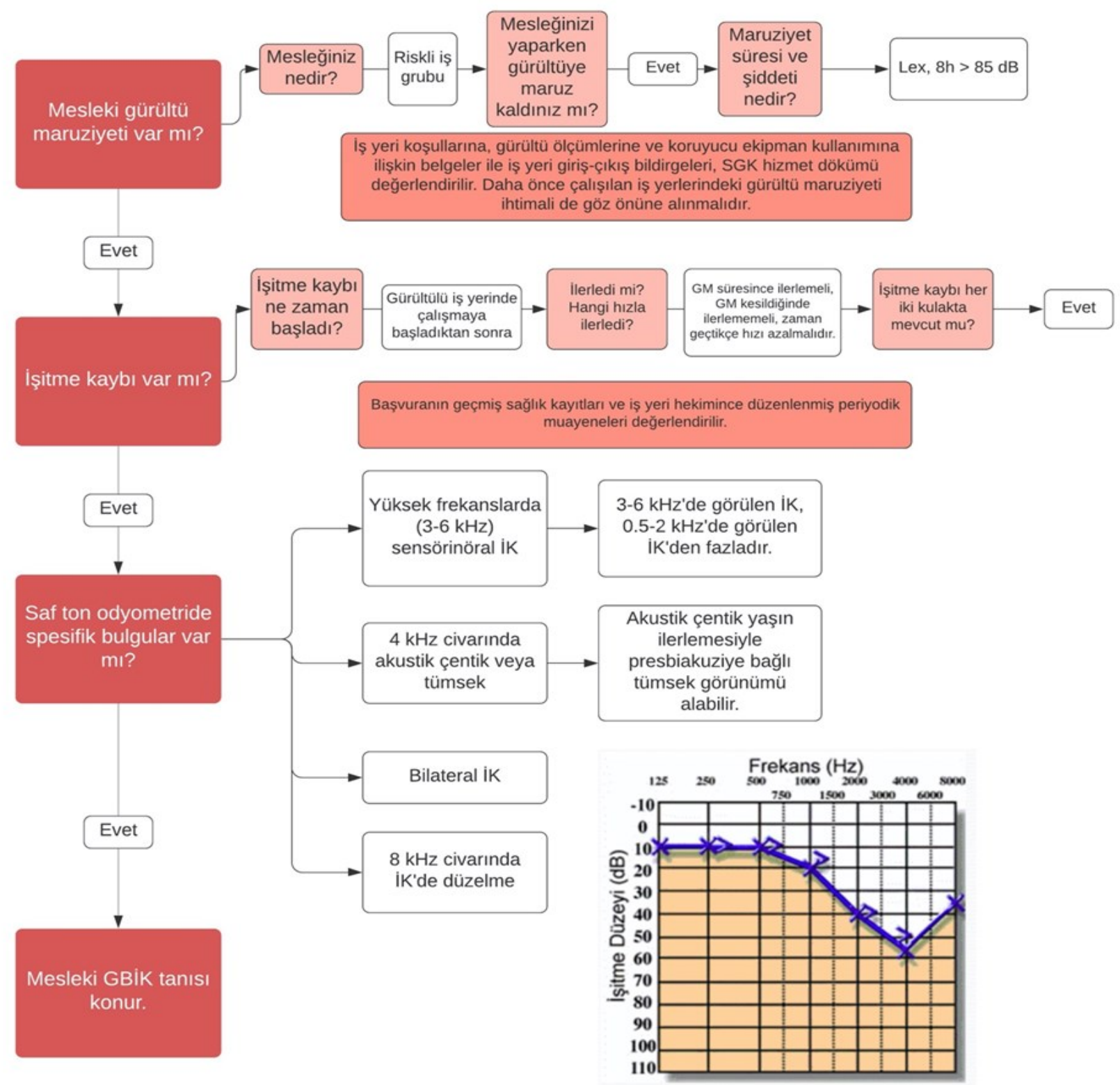

Lex, 8h: 8 saatlik günlük çalışma süresince maksimum maruziyet değeri, İ: işitme kaybı, GBiK: gürültüye bağlı işitme kaybı, GM: gürültü maruziyeti 
lu Raporları Hakkında Yönetmelik ile çok benzer olarak düzenlenmiştir [20].

\section{G. TS 2607 ISO 1999 Standardı}

Bu standart “Akustik-İş yerinde maruz kalınan gürültünün tayini ve bu gürültünün sebep olduğu işitme kaybının tahmini” hususuna yönelik standart olarak kabul edilir [21].

\section{H. TS EN ISO 9612-2009 Standardı}

Bu standart ise "Akustik-Mesleki Gürültü Maruziyetinin Belirlenmesi-Mühendislik Metodu” için kabul edilen standarttır [21].

Türkiye'de mesleki GBİK ile ilgili mevzuat incelendiğinde tanı konulabilmesi için üç temel kriterin bulunması gerektiği görülmektedir. Bunlar; kişinin Çalışanların Gürültü ile İlgili Risklerden Korunmalarına Dair Yönetmelikte belirtilen gürültünün maksimum maruziyet değerinin üzerinde olduğu bir işte çalışması, işitme kaybının bu maruziyet sonrasında, Tablo 1'de listelenen özelliklere sahip olması ve işitme kaybının tek tanı aracı olarak belirtilen saf ton odyometri ile belgelenmesidir. Yasal mevzuat doğrultusunda mesleki GBİK'nin medikolegal olarak değerlendirilmesinde kullanılabilecek bir algoritma önerisi Tablo 2'de verilmiştir.

Meslek Hastalıkları ve İş ile İlgili Hastalıklar Tanı Rehberi’ne göre saf ton odyometri GBİK değerlendirmesinde tek tanı aracı olarak belirtilmiştir [18]. Saf ton odyometrinin yapılış şekli, kapsamı ve sonuçlarının değerlendirilmesi
Tablo 3'te özetlenmiştir.

Mesleki GBİK tanısını koyabilmek için Tablo 2'de belirtilen 3 kriterin (gürültü maruziyeti ile işitme kaybının belgelenmesi ve saf ton odyometri bulguları) de bulunması gerekmektedir. Ancak bazı olgularda işitme kaybının başka bir nedeni bulunabileceği gibi, bu başka nedenler ile gürültünün ortak etkisiyle de işitme kaybı gelişebilmektedir. Anamnez sırasında gürültü dışı nedenlerin sorgulanması, ek muayene bulguları ve saf ton odyometri dışındaki işitme değerlendirme yöntemlerinden faydalanılmasının yanında, Kulak Burun Boğaz uzman doktorlarından konsültasyon istenmesi de gerekebilir. Bu bakımdan nedensellik bağı kurmakta zorlanılan olgularda başvurulabilecek ek değerlendirmeler Tablo 3'te özetlenmiştir.

Değinilmesi gereken bir diğer nokta da, işitme kaybının tespiti için yapılan “Odyometri” testinin objektif bir test olmaması hususudur. Bu test sırasında, kişinin kulağına farklı frekans ve desibel düzeylerinde sesler gönderilmektedir ve test yapılan kişi sesleri duyduğunda, tanımlanan bir düğmeye basmaktadır. Bir başka deyişle, test sırasında, test yapılan kişi sesi duyup düğmeye basmayabilmekte veya sesi duymayıp düğmeye basabilmektedir. Dolayısıyla test sırasında temaruz (simülasyon) olasılığı vardır. Yani, test yapılan kişinin, testin kötü çıkması sonucunda sekonder kazancı durumu mevcutsa, testi yanıltması mümkündür [22]. Tarafımızdan yapılan değerlendirmelerde odyometri ile ilgili çelişkili sonuçlarla sık karşılaşılmakta olup, simülasyon yapılması, testi yapan odyometristlerin

Tablo 3: Saf Ton Odyometri

\begin{tabular}{ll}
\hline Kapsamı & Periferik işitme değerlendirilir. 125-8000 Hz aralığındaki frekanslarda ölçüm yapılır. \\
\hline Uygulama kriterleri & $\begin{array}{l}\text { Gürültülü ortamdan en az } 14 \text { saat (ideal } 48 \text { saat) uzaklaştiktan sonra, bu şart sağlanamıyorsa } 80 \text { dB üzerindeki gürültüler } \\
\text { içlçüm her frekans için } 3 \text { kez tekrarlanır. }\end{array}$ \\
\hline GBí & En belirgin ve en erken bulgu $4000 \mathrm{~Hz}$ 'de görülen akustik çentiktir. \\
& 3000-6000 Hz'de (yüksek frekanslarda) belirgin işitme kaybı görülür. \\
& İşitme kaybı alçak frekanslarda $40 \mathrm{~dB}^{\prime} \mathrm{i}$, yüksek frekanslarda $75 \mathrm{~dB}$ 'i geçmemelidir.
\end{tabular}


Tablo 4: Ek Değerlendirmeler
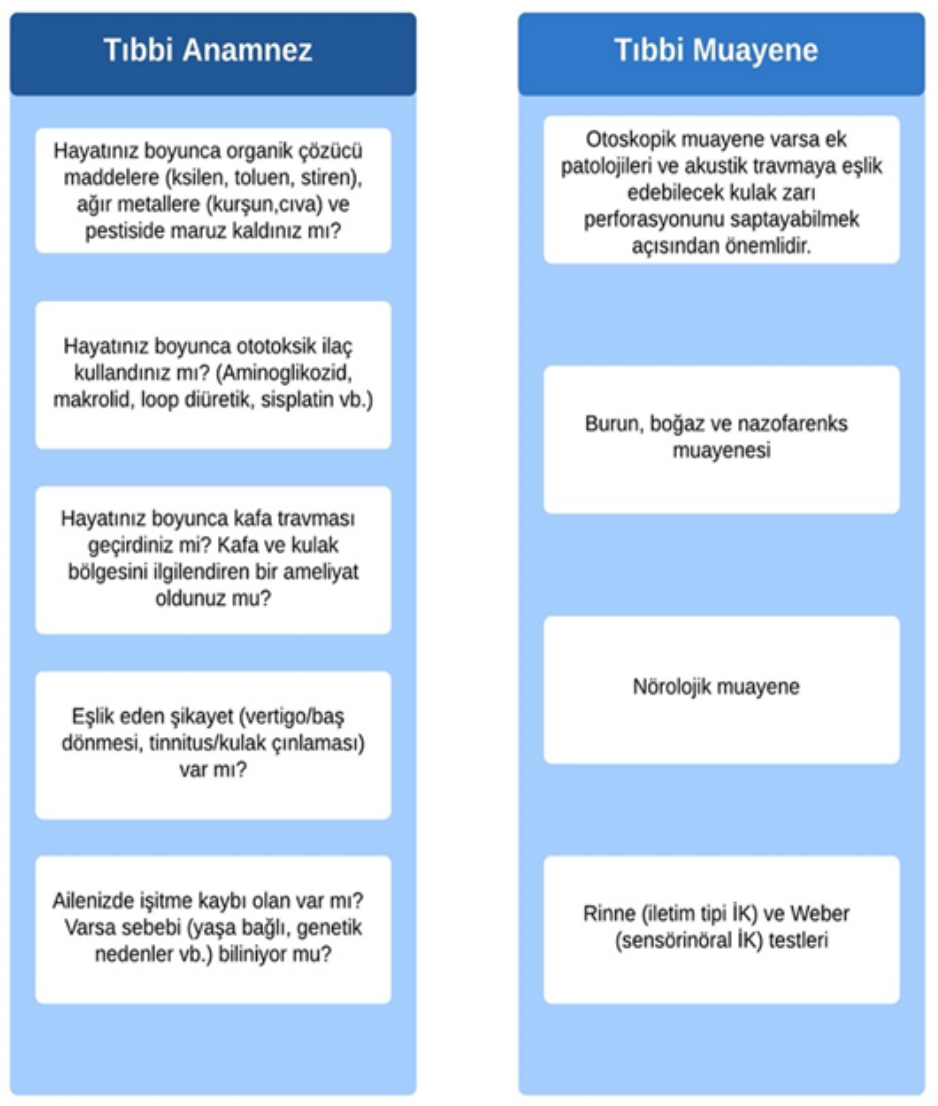

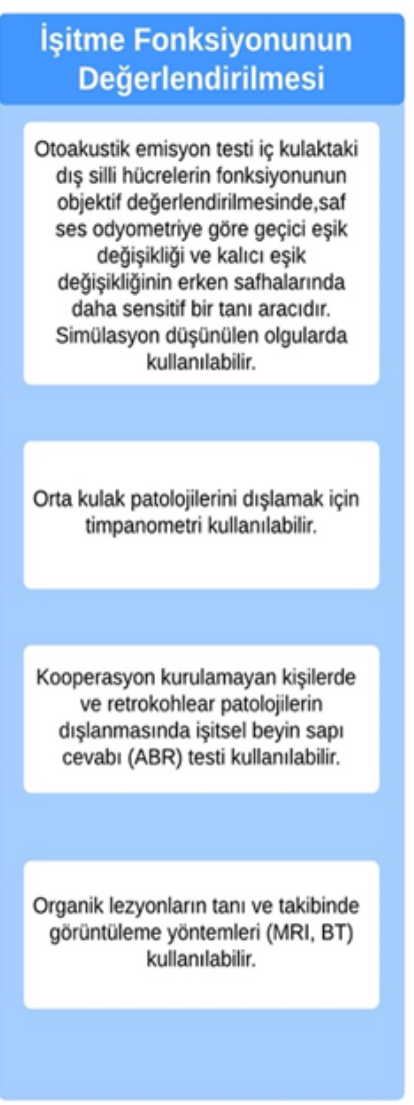

farklı olması gibi faktörlerin bu çelişkilere neden olduğu düşünülmektedir. Bu nedenle medikolegal değerlendirmenin kesin sonuç içermesi için ülkemizde yakın dönemde kullanılmaya başlanan, özellikle yeni doğanların işitme kayıplarının değerlendirilmesinde kullanılan, objektif bir test olan BERA (brainstem evoked response audiometry, işitsel beyin sapı cevabı) isimli yöntem önerilmektedir. Song ve ark. yaptıkları çalışmada, bu yöntemin test tekrarlanabilirliği açısından yüksek derecede güvenilir olduğunu belirtmiştir [23]. BERA testi, temaruz olasılığını en aza indirgemekte olup odyometrik incelemeye göre daha güvenilirdir. Yöntemin yasal açıdan bir tanı aracı olarak belirtilmemiş olması nedeniyle medikolegal amaçla kullanımı için daha çok araştırmaya ihtiyaç duyulmaktadır.

\section{AYIRICI TANIDA GÖZ ÖNÜNE ALINMASI GEREKLİ DURUMLAR}

Tablo 4'te özetlenen ek değerlendirmelerin dışında presbiakuzi, sigara kullanımı ve asimetrik işitme kayıplarının tanıyı zorlaştırıcı etkisi medikolegal yaklaşımda da sıklıkla karşımıza çıkabilmektedir.

\section{A. Sigara Kullanımının İşitme Kaybı Üzerine Etkisi}

Sigara kullanımı işitme üzerine periferik vasküler değişiklikler yolu ile olumsuz etkiler göstermektedir. Sigara kullanımına bağlı olarak kan viskositesindeki artış, oksijen düzeyindeki düşüş, kapiller vazokonstriksiyon ve koklear hipoksi sensörinöral işitme kaybı üzerinde etki gösteren önemli faktörlerdir [24, 25]. Yapılan çalışmalarda sigaranın GBİK’ye etkisi üzerine farklı sonuçlar elde edilmiştir. Bazı 
çalışmalarda sigara ve gürültünün additif etkisi olabileceği, bazılarında sinerjistik etkinin var olabileceği gösterilmiştir [26, 27, 28]. Diğer yandan sigaranın, GBİK üzerine etkisinin sınırlı olabileceğine dair çalışmalar da vardır [29]. Ancak özellikle son dönem çalışmalara bakıldığında, sigara içiminin, GBİK üzerine olumsuz etkileri belirgin hale gelmektedir [24, 25].

\section{B. Asimetrik Gürültüye Bağlı İşitme Kaybı}

Tek taraflı işitme kaybının tıbbi etiyolojik faktörleri Tablo 5'te sıralanmıştır.

Tablo 5: Tek Taraflı İşitme Kaybında Etiyoloji

\begin{tabular}{c}
\hline Akustik Nörinoma \\
Kafa Travması \\
Enfeksiyöz ve Vasküler Hastalıklar \\
Meniere Hastalığı \\
Perilenfatik Fistül \\
Konjenital ve Genetik Nedenler \\
\hline
\end{tabular}

Tek taraflı işitme kaybında bir kulağın işitmesi normal seviyede iken, asimetrik işitme kaybında her iki kulakta işitme kaybı şiddetlerinin farklı olması kastedilmektedir. Asimetrik GBİK’ye yol açabilecek faktörler açısından koruyucu ekipmanın tek taraflı kullanımı, kulaklar arasında gürültüye duyarlılık açısından farklılık olması, başın gölge etkisi (head shadowing effect - yüksek frekanslı seslerin kısa dalga boyuna sahip olması sonucunda bir tarafta var olan gürültünün başı aşamayarak diğer kulağa daha az etki etmesi) gibi teoriler öne sürülmüştür [30, 31]. Ancak ülkemizde Meslek Hastalıkları ve İş ile İlgili Hastalıklar Tanı Rehberi'ne göre GBİK daima bilateral olarak kabul edilmektedir [18]. Asimetrik GBİK olgularında iki kulak arasındaki işitme kaybı farkının gürültüye bağlı olup olamayacağı konusu halen tartışmalıdır.

Masterson ve ark. yaptığ 4735 vakayı içeren derleme çalışmasında GBİK’nin \%2.4 ile \%22.6'sı arası değişen bir oranda asimetrik olguların görülebildiği belirtilmiştir. Bu çalışmada sol ve sağ kulak arasında $0.5-8 \mathrm{kHz}$ arasındaki herhangi bir frekansta görülen 15 dB'den fazla fark asimetrik işitme kaybı olarak, gürültü ise günde 8 saatten ve 85 dB'den fazla şiddette gürültüye en az 2 sene maruz kalmak olarak kabul edilmiştir. Vakaların çoğunluğunda (\%6080 'inde) sol taraftaki işitme kaybının daha fazla olduğu bulunmuştur [32].

\section{Presbiakuzi (Yaşlanmaya Bağlı İşitme Kaybı) ve Gü- rültüye Bağlı İşitme Kaybı}

Presbiakuzi yaşın ilerlemesiyle ortaya çıkan ve geriatrik popülasyonun yaklaşık yarısını etkileyen işitme kaybı sürecidir. İç kulak yapılarının yaşa bağlı dejenerasyonu sonucu gelişir, progresif bir seyir izler, bilateral ve simetrik bir sensörinöral işitme kaybıdır. Gürültüye ve yaşa bağlı işitme kaybı arasındaki etkileşim hala tam olarak anlaşılamamıştır. Gürültüye bağlı işitme kaybı geliştikten sonra gürültü maruziyeti devam etse bile, işitme kaybı şiddetinde meydana gelen artışın daha yüksek oranda yaşın etkisine bağlanabileceğini savunan çalışmalar bulunmaktadır [33]. Buna karşın Lee ve ark. ile Hederstierna ve ark. yaptığı prospektif kohort çalışmalarında; katılımcıların belirli zaman aralıklarında yapılan saf ton odyometrilerindeki yıllık işitme eşik değer artış hızlarında, gürültüye maruz kalan ve kalmayan gruplar arasında anlamlı bir fark bulunamamıştır. Bu çalışmalar da gürültü ve yaşın additif etkisinin olduğunu, yani birinin diğerini etkilemediğini göstermektedir [34, 35].

\section{SONUÇ}

Mesleki GBİK ile ilgili en büyük zorluk, tespit edilebilen vaka sayısının azlığıdır. Bu noktada vurgulamak gerekir ki, ülkemiz çalışanları daha az risk altında değildir. Vaka sayısının az olmasının en önemli nedeninin, vakalardaki yetersiz tıbbi destek olduğu düşünülebilir. GBİK tanısı koymaktaki en büyük zorluklardan birisi, işitme kaybında rol oynayan diğer faktörlerin etkilerinin kontrol edilememesidir. Örneğin yaş ya da sigara kullanımı gibi faktörler 
karışıklığa sebep olmaktadır.

Bu çalışmada GBİK ile ilgili yasal durum ortaya konmuştur. Ayrıca GBİK ve üzerine etkileri olabilecek sık tıbbi durumlar değerlendirilmiştir. Son olarak, GBİKnnin medikolegal değerlendirilmesi esnasında izlenebilecek bir algoritma önerilmiştir. Bu algoritmanın, mesleki GBİK tanısında kullanılmasının gerçek vakaların daha kolay yakalanmasını sağlayacağına inanmaktayız.

\section{KAYNAKÇA}

[1] Basner M, Babisch W, Davis A, et al. Auditory and non-auditory effects of noise on health. Lancet. 2014;383(9925):1325-1332. doi:10.1016/S01406736(13)61613-X.

[2] Nelson DI, Nelson RY, Concha-Barrientos M, Fingerhut $\mathrm{M}$. The global burden of occupational noiseinduced hearing loss. Am J Ind Med. 2005;48(6):446 -458. doi:10.1002/ajim.20223.

[3] Tak S, Davis RR, Calvert GM. Exposure to hazardous workplace noise and use of hearing protection devices among US workers-NHANES, 1999-2004. Am J Ind Med. 2009;52(5):358-371. doi:10.1002/ ajim. 20690 .

[4] Masterson EA, Tak S, Themann CL, et al. Prevalence of hearing loss in the United States by industry. Am J Ind Med. 2013;56(6):670-81. doi:10.1002/ ajim. 22082.

[5] Ozturk A, Ergor G, Demiral Y, Ergor A, Tapci N. Döküm iş kolunda gürültüye bağlı işitme kayıpları sıklığı ve etkileyen etmenlerin değerlendirilmesi. Türk Tabipleri Birliği Mesleki Sağlık ve Güvenlik Dergisi. 2007;25:40-46. https://www.ttb.org.tr/ dergi/index.php/msg/article/view/224/206. Erişim tarihi: 4 Ocak 2020.

[6] Daniell WE, Swan SS, McDaniel MM, Camp JE, Cohen MA, Stebbins JG. Noise exposure and hearing loss prevention programmes after 20 years of regulations in the United States [published correction appears in Occup Environ Med. 2006 Jun;63
(6):436]. Occup Environ Med. 2006;63(5):343-351. doi:10.1136/oem.2005.024588.

[7] 5510 Sayılı Kanunun 4-1/a Maddesi Kapsamındaki Sigortalılardan Meslek Hastalığına Tutulanların Tanılarına ve Cinsiyete Göre Dağılımı, 2018. Sosyal Güvenlik Kurumu. http:/www.sgk.gov.tr/wps/ portal/sgk/tr/kurumsal/istatistik/

sgk_istatistik_yilliklari Yayınlanma tarihi: 2020 Erişim tarihi: 26 Nisan 2020.

[8] Mitchell J, McCombe A. Noise-induced hearing loss. Journal of ENT Masterclass. 2009;2(1):107-111. https://entmasterclass.com/journals/

ENT_Journal_2009.pdf\#page $=109$. Accessed January $15,2020$.

[9] Le TN, Straatman LV, Lea J, Westerberg B. Current insights in noise-induced hearing loss: a literature review of the underlying mechanism, pathophysiology, asymmetry, and management options. J Otolaryngol Head Neck Surg. 2017;46(1):41. doi:10.1186/s40463-017-0219-x.

[10] Kenar F, Aycicek A. Endüstriyel odyoloji ve gürültüye bağlı işitme kayıpları. Turkiye Klinikleri J E.N.T.Special Topics. 2015;8(2):132-136. https:// www.turkiyeklinikleri.com/article/en-endustriyelodyoloji-ve-gurultuye-bagli-isitme-kayiplari71968.html. Erişim tarihi: 17 Ocak 2020.

[11] Sliwinska-Kowalska M, Kotylo P. Evaluation of individuals with known or suspected noise damage to hearing. Audiological Medicine. 2007;5(1):54-65. doi:10.1080/16513860601181442.

[12] Coles RR, Lutman ME, Buffin JT. Guidelines on the diagnosis of noise-induced hearing loss for medicolegal purposes. Clin Otolaryngol Allied Sci. 2000;25 (4):264-273 $\quad$ doi: 10.1046/j.13652273.2000.00368.x.

[13] Das S, Mulheran M, Brewster M, Banerjee AR. Noise-induced hearing loss - An examination of the methods of assessment in a cross-sectional study of 87 industrial workers. Clin Otolaryngol. 2018;43(2):591 -597. doi: 10.1111/coa.13028.

[14] John AB, Kreisman BM, Pallett S. Validity of hearing impairment calculation methods for prediction of self 
-reported hearing handicap. Noise Health. 2012;14 (56):13-20. doi: 10.4103/1463-1741.93321.

[15] Çalışanların Gürültü İle İlgili Risklerden Korunmalarına Dair Yönetmelik. (2013, 28 Temmuz). Resmi Gazete (Sayı: 28721). Erişim adresi: https:// www.mevzuat.gov.tr/Metin.Aspx?

MevzuatKod=7.5.18647\&MevzuatIliski=0.

[16] 6331 Sayılı İş Sağlığı ve Güvenliği Kanunu. (2012, 30 Haziran). Resmi Gazete (Sayı: 28339). Erişim adresi: https://www.mevzuat.gov.tr/ MevzuatMetin/1.5.6331.pdf.

[17] T.C. Çalışma ve Sosyal Güvenlik Bakanlığı, İş Sağlığı ve Güvenliği Genel Müdürlüğü. (2018). Çalışanların Gürültü İle İlgili Risklerden Korunmalarına İlişkin Uygulama Rehberi. Erişim adresi: https:// www.ailevecalisma.gov.tr/medias/9187/\%C3\%

A7alisanla-

rin_guerueltue_ile_ilgili_risklerden_korunmalarina_il iskin_uygulama_rehberi_30052018.pdf.

[18] T.C. Çalışma ve Sosyal Güvenlik Bakanlığı, İş Sağlığı ve Güvenliği Genel Müdürlügü. (2015). Meslek Hastalıkları ve İş ile İlgili Hastalıklar Tanı Rehberi. Erişim adresi: http://www.isgum.gov.tr/rsm/file/isgdoc/ isgip/isgip_saglik_tani_rehberi.pdf.

[19] Özürlülük Ölçütü, Sınıflandırma ve Özürlülere Verilecek Sağlık Kurulu Raporları Hakkında Yönetmelik. (2013, 30 Mart) Resmi Gazete (Sayı: 28603). Erişim adresi: https:/www.resmigazete.gov.tr/ eskiler/2013/03/20130330-4.htm.

[20] Erişkinler İçin Engellilik Değerlendirmesi Hakkında Yönetmelik. (2019, 20 Şubat). Resmi Gazete (Sayı: 30692). Erişim adresi: https:// www.resmigazete.gov.tr/eskiler/2019/02/201902202.htm.

[21] T.C. Çalışma ve Sosyal Güvenlik Bakanlığı, İş Sağlığı ve Güvenliği Genel Müdürlüğü. (2015). Kişisel Gürültü Maruziyeti Ölçüm Metodları. Erişim adresi: http://www.isgum.gov.tr/rsm/file/9612.pdf.

[22] Rickards FW, De Vidi S. Exaggerated hearing loss in noise induced hearing loss compensation claims in Victoria. Med J Aust. 1995;163(7):360-363. doi:10.5694/j.1326-5377.1995.tb124629.x.
[23] Song JH, Nicol T, Kraus N. Test-retest reliability of the speech-evoked auditory brainstem response. Clin Neurophysiol. 2011;122(2):346-355. doi:10.1016/ j.clinph.2010.07.009.

[24] Pouryaghoub G, Mehrdad R, Mohammadi S. Interaction of smoking and occupational noise exposure on hearing loss: a cross-sectional study. BMC Public Health. 2007;7:137. doi:10.1186/1471-2458-7-137.

[25] Tao L, Davis R, Heyer N, et al. Effect of cigarette smoking on noise-induced hearing loss in workers exposed to occupational noise in China. Noise Health. 2013;15(62):67-72. doi: 10.4103/14631741.107159.

[26] Mizoue T, Miyamoto T, Shimizu T. Combined effect of smoking and occupational exposure to noise on hearing loss in steel factory workers. Occup Environ Med. 2003;60(1):56-59. doi:10.1136/ oem.60.1.56.

[27] Cruickshanks KJ, Klein R, Klein BEK, Wiley TL, Nondahl DM, Tweed TS. Cigarette Smoking and Hearing Loss: The Epidemiology of Hearing Loss Study. JAMA. 1998;279(21):1715-1719. doi:10.1001/jama.279.21.1715.

[28] Mohammadi S, Mazhari MM, Mehrparvar AH, Attarchi MS. Effect of simultaneous exposure to occupational noise and cigarette smoke on binaural hearing impairment. Noise Health. 2010;12 (48):187囚190. doi: 10.4103/1463-1741.64975.

[29] Starck J, Toppila E, Pyykkö I. Smoking as a risk factor in sensory neural hearing loss among workers exposed to occupational noise. Acta Otolaryngol. 1999; 119(3):302区305. doi: $10.1080 / 00016489950181288$.

[30] Fernandes SV, \& Fernandes CM. Medicolegal significance of asymmetrical hearing loss in cases of industrial noise exposure. J Laryngol Otol. 2010;124 (10):1051-1055. doi:10.1017/S0022215110001258.

[31] Berg RL, Pickett W, Linneman JG, Wood DJ, Marlenga B. Asymmetry in noise-induced hearing loss: evaluation of two competing theories. Noise Health 2014;16(69):102-107. doi:10.4103/14631741.132092 . 
[32] Masterson L, Howard J, Liu ZW, Phillips J. Asymmetrical Hearing Loss in Cases of Industrial Noise Exposure: A Systematic Review of the Literature. Otol Neurotol. 2016;37(8):998-1005. doi:10.1097/ MAO.0000000000001104.

[33] Albera R, Lacilla M, Piumetto E, Canale A. Noiseinduced hearing loss evolution: influence of age and exposure to noise. Eur Arch Otorhinolaryngol 2010;267(5):665-671. doi:10.1007/s00405-0091096-3.

[34] Hederstierna C, Rosenhall U. Age-related hearing decline in individuals with and without occupational noise exposure. Noise Health. 2016;18(80):21-25. doi:10.4103/1463-1741.174375.

[35] Lee FS, Matthews LJ, Dubno JR, Mills $\mathrm{JH}$. Longitudinal study of pure-tone thresholds in older persons. Ear Hear. 2005;26(1):1-11. doi:10.1097/00003446-200502000-00001. 